\title{
Association between Major Depression and Type 2 Diabetes Mellitus: a Meta-Analysis and Meta-Regression of Observational Studies

\section{Abstract}

The purpose of this review was to identify the prevalence of major depression in individuals with type 2 diabetes by means of a systematic review and meta-analysis. An electronic search was conducted for relevant studies published from January 1988 to December 2014. Cross-sectional and case-control studies in adults that evaluated the prevalence of major depression in individuals with type 2 Diabetes Mellitus were included. Meta-regression and sensitivity analyses were used to identify the sources of heterogeneity. Publication bias was assessed using a funnel plot and Egger's test. After the selection process, 18 cross-sectional and four case-control studies were included in the meta-analysis. In total, the occurrence of major depression was investigated in 5554 patients with diabetes mellitus type 2 . The prevalence of major depression varied from $6.67 \%(95 \% \mathrm{Cl}: 4.54 \%$ - 9.38\%) to $55.38 \%$ (95\% Cl: $42.53 \%-67.73 \%)$, with an overall average of $21.13 \%$ (95\% Cl: $15.80 \%-27.66 \%)$. In American continent, the prevalence was $20.83 \%\left(95 \% \mathrm{Cl}: 13.12 \%-31.43 \%\right.$; $\left.{ }^{2}=96.8 \%\right)$, and in Europe it was $18.00 \%$ (95\% Cl: $\left.8.58 \%-33.91 \% ;{ }^{2}=93.8 \%\right)$. Both were lower than the rate in Asia, which was $23.49 \%$ (95\% Cl: $\left.15.63 \%-33.74 \% ;\left.\right|^{2}=90.8 \%\right)$. Meta-regression analysis found no evidence that the analyzed cofactors represented the cause of the heterogeneity seen. The approximately symmetrical distribution of the points in Funnel Plot suggests an absence of publication bias that was confirmed by Egger's test $(p=0.2345)$. Based on the data collected, we can infer that the prevalence of major depression in individuals with type 2 diabetes was high, independent of geographic location.

\section{Keywords}

Type 2 Diabetes Mellitus; Major Depressive Disorder; Systematic Review; Meta-analysis; Evidence-Based Practice.
Abigail Lopes ${ }^{1,2}$, Ingrid Schweigert Perry2, Daniela Vicente Bavaresco', Lisiane Tuon ${ }^{1,2}$, Luciane Bisognin Ceretta, Priscyla Waleska Simões ${ }^{1,2}$, Rita Suselaine Vieira Ribeiro ${ }^{1}$

1 Multidisciplinary Residency Program in Primary Care/Family Health. Universidade do Extremo Sul Catarinense (UNESC), Criciúma, SC, Brazil.

2 Graduate Program in Public Health (PPGSCol). Universidade do Extremo Sul Catarinense Criciúma (UNESC), SC, Brazil.

Contact information:

Rita Suselaine Vieira Ribeiro/Priscyla Waleska Simões.

Multidisciplinary Residency Program in Primary Care/Family Health.

Address: Universidade do Extremo Sul Catarinense (UNESC). Av. Universitária, 1105. Bairro Universitário, CEP: 88806 000. Criciúma-SC.

Tel: $+55483431-2500$.

\section{”rsv@unesc.net}

”pri@unesc.net 


\section{Introduction}

Diabetes Mellitus (DM) is an important public health issue because it increases the risk of cardiopathies, stroke and microvascular complications, such as blindness, kidney failure and peripheral neuropathy [1].

In general, DM is characterized by high levels of glucose in the blood as a result of insulin failure, and it is considered a heterogeneous disease because of its multiple aetiologies [1].

Type 2 Diabetes Mellitus (T2DM) is the most common form of this disease. In addition to factors such as lifestyle, age, pregnancy and obesity, genetics may be involved in the pathophysiology [1].

The relationship between DM and psychiatric disorders has been described in many studies. These studies indicate that depression is considered a psychiatric comorbidity associated with DM that affects approximately $20 \%$ of patients with DM $[2,3]$.

Depression as a psychiatric disorder is defined by significant changes in mood in phases that vary in intensity and duration. The clinical profile is characterized by depressed mood, anhedonia, decreased ability to think, concentrate or make decisions, changes in sleep and appetite, reduced sexual interest, and social withdrawal, among other symptoms [4].

Some studies suggest that people with diabetes are more likely to develop depression [5, 6]. Even an early diagnosis of diabetes is strongly linked to the relative risk of depression and increased blood sugar levels [7]. Longitudinal studies suggest that comorbid DM and depression is associated with high mortality rates [8-10]. The 5th edition of the Diagnostic and Statistical Manual of Mental Disorders (DSM) [4] reports that the prevalence of Major Depressive Disorder MDD in the USA is approximately $7 \%$ and that it is more commonly observed in women (rates 1.5 to 3 times higher than in men) starting in adolescence [4, 11]. Some researchs suggests that there is a higher mortality associated with depressive symptoms in elderly patients with chronic diseases, such as DM $[12,13]$. Furthermore, a diagnosis of depression infers an increased risk of non-adherence to medical recommendations [14].

Some studies have suggested an association between MDD and T2DM, which can lead to impaired glucose control and worsen the clinical condition of the individual $[4,11]$. Several meta-analyses have investigated the association between depression and T2DM [2, 5-7, 15-18]. However, they did not evaluate the relationship between T2DM and the severity of depression. There are few systematic reviews and meta-analyses that have previously evaluated the association of severe depression with T2DM, this study aims to provide evidence for this relationship. The findings from this research may help in the development of early screening strategies for diagnosis of depression in patients with T2DM, resulting in a better quality of life, improved adherence to and success of treatments and empowerment of individuals and professionals who care for these conditions in their daily lives.

This paper aims to estimate the prevalence of MDD in people with T2DM through a systematic review and meta-analysis.

\section{Methods}

\section{Search strategy}

An electronic search was conducted on MEDLINE (via PubMed), EMBASE, LILACS, Scopus, Cochrane's Central Register of Controlled Studies, IBECS, BIOSIS and Web of Science for relevant studies published from January 1988 to December 2014, using MeSH descriptors and synonyms, including "depression", "major depressive disorder", "severe depression", and "Type 2 Diabetes Mellitus". The terms were combined using the Boolean operators "AND", "OR" and "NOT".

Later, we searched for references that were listed in all of the primary studies found through the electronic search and researched the grey literature. Our meta-analysis addressed only studies in humans and there were no language restrictions. 
Initial analysis of the identified titles and abstracts from the database search was performed independently by four researchers. Potentially relevant publications that met the necessary criteria were selected to be read in full by the same researchers. In both phases, disagreements regarding the inclusion or exclusion of a study were resolved by consensus, involving another researcher.

\section{Study selection}

We collected data related to the publication year, country, age, gender, and other sociodemographic characteristics of the subjects in addition to the number of individuals with MDD and T2DM.

For the meta-analysis, the data on the prevalence of MDD in subjects with T2DM were grouped using a random effects model $[19,20]$. The heterogeneity was quantified by $\tau^{2}$, Cochran's $\mathrm{Q}$ test, and the inconsistency presented by $I^{2}[21,22]$, which describes the percentage of variability that is due to the variability between studies and not to chance [19].

Because of the identified heterogeneity, sensitivity analyses were performed to identify the associated cofactors for each continent where a study was conducted. Potential cofactors were also analyzed using meta-regression (using the variables publication year, age, duration of diabetes, duration of MDD, and HbA1c mean).

In addition, case-control studies were summarized using the random effects method [19, 20], and the calculation of heterogeneity was also quantified by $\tau^{2}, \mathrm{Q}$ Cochran's $\mathrm{Q}$ test, and the inconsistency by $I^{2}[21,22]$. In studies in which only one of the $2 \times 2$ contingency table cells showed a value of zero, the value added was 0.5 to facilitate the calculation of the odds ratio. However, studies in which the value 0 (zero) occurred in more than two cells were excluded from the analysis [19, 23, 24].

The possibility of publication bias (the trend that studies with negative results are less likely to be published) was evaluated by the Egger's test [25] and analysis funnel plots [26]. In these charts, each point represents one study, a measure of effect or prevalence, and standard error, for example [26]. In cross-sectional studies, a logit transformation was conducted to analyze the prevalence of publication bias.

Meta-analysis was performed using R 3.1.1 software (Comprehensive R Archive Network, http:// cran.r-project.org/), and the graphical representation of the results was made using forest plots [2729].

\section{Results}

Through data collection from the databases mentioned above, we found a total of 387 publications with the potential for inclusion in our study and identified one additional study, resulting in 388 references to be evaluated. Next, we analyzed the title and abstract, of which 165 were selected to be read in full. After reading the full articles, 22 articles were selected, with the remaining excluded because of data duplication, data failure, association with specific diseases, a non-validated method or unclear diagnosis, and/or an unspecified subtype of diabetes. These 18 cross-sectional studies and four control cases were included in the meta-analysis. This process is shown in Figure 1. The researcher agreement on the eligibility of the studies was excellent $(k=0.91)$.

Studies were published between 1995 and 2013 and evaluated 5554 patients with T2DM. The prevalence of MDD ranged from $6.67 \%(95 \% \mathrm{Cl}$ : $4.54 \%-9.38 \%)$ to $55.38 \%(95 \% \mathrm{Cl}: 42.53 \%-$ $67.73 \%)$, with an overall average of $21.13 \%(95 \%$ Cl: $15.80 \%-27.66 \%)$, as shown in Figure 2. Heterogeneity found in the evaluation of cases was high $\left(I^{2}=95.6 \% ; \tau^{2}=0.5506 ; p<0.0001\right)$. Of the included studies, three were conducted in Europe [30-32], six in Asia [33-38], and nine in the Americas (North, Central and South) [39-47]. (Figure 2)

Sensitivity analyses were performed for each country in order to examine the heterogeneity. In 
Figure 1: Flow chart of selection of items.

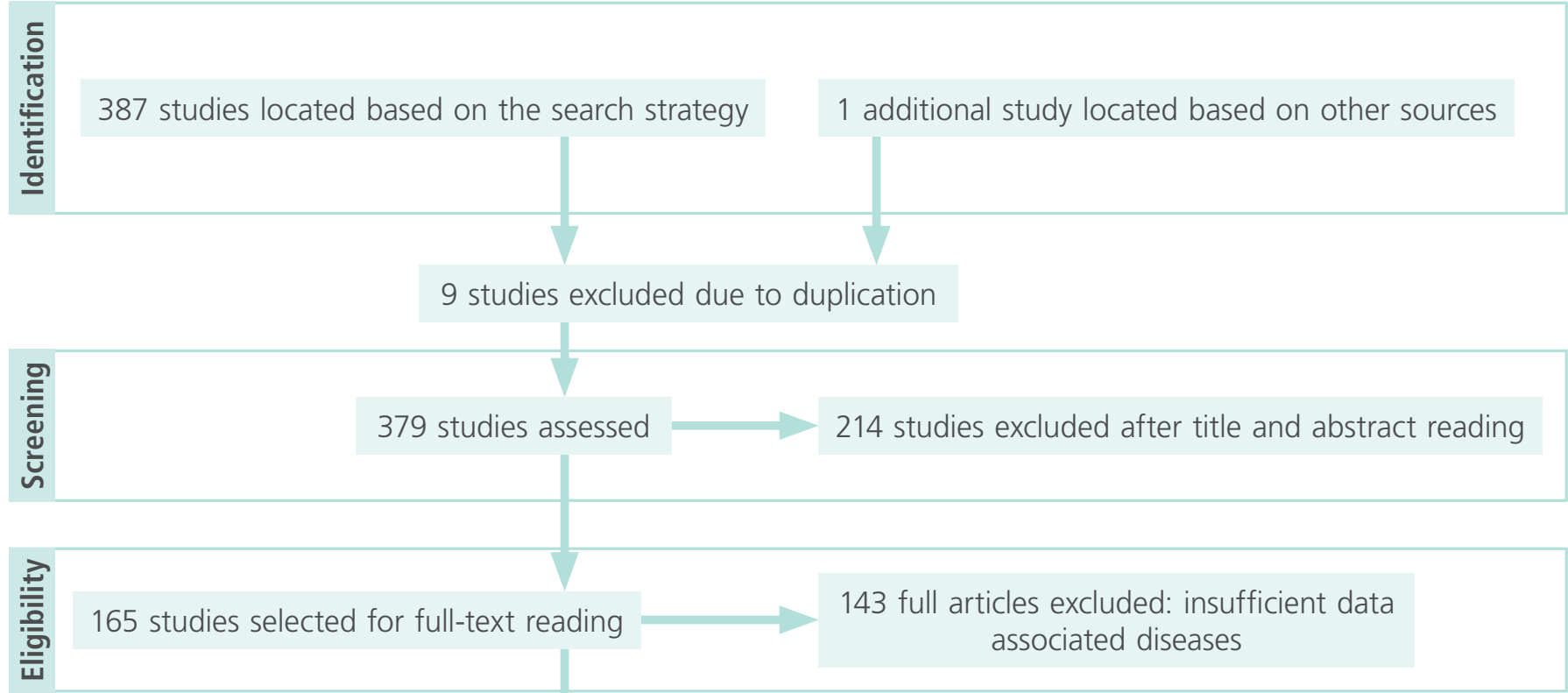

\section{2 studies included in the qualitative analysis}

Figure 2: Prevalence of Major Depression in Type 2 Diabetes Mellitus.

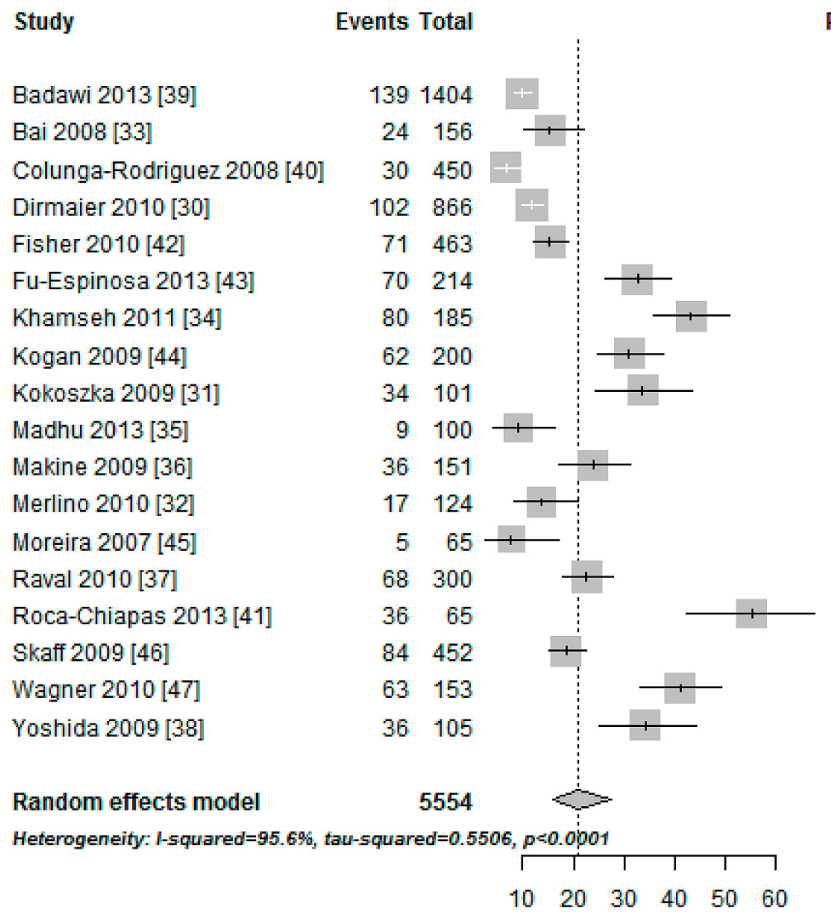

Prop (in \%)

$95 \%-\mathrm{Cl} \mathrm{W(random)}$

$\begin{array}{rr}9.90[8.39 ; 11.58] & 5.9 \% \\ 15.38[10.11 ; 22.02] & 5.5 \% \\ 6.67[4.54 ; 9.38] & 5.6 \% \\ 11.78[9.71 ; 14.11] & 5.9 \% \\ 15.33[12.17 ; 18.95] & 5.8 \% \\ 32.71[26.47 ; 39.44] & 5.8 \% \\ 43.24[35.99 ; 50.71] & 5.8 \% \\ 31.00[24.67 ; 37.91] & 5.7 \% \\ 33.66[24.56 ; 43.75] & 5.5 \% \\ 9.00[4.20 ; 16.40] & 4.9 \% \\ 23.84[17.29 ; 31.45] & 5.6 \% \\ 13.71[8.19 ; 21.04] & 5.3 \% \\ 7.69[2.54 ; 17.05] & 4.3 \% \\ 22.67[18.05 ; 27.83] & 5.8 \% \\ 55.38[42.53 ; 67.73] & 5.4 \% \\ 18.58[15.10 ; 22.48] & 5.8 \% \\ 41.18[33.29 ; 49.41] & 5.7 \% \\ 34.29[25.30 ; 44.19] & 5.6 \% \\ 21.13[15.80 ; 27.66] & 100 \%\end{array}$

$21.13[15.80 ; 27.66] \quad 100 \%$ 
the Americas, the prevalence of MDD was $20.83 \%$ (95\% Cl: $\left.13.12 \%-31.43 \% ; I^{2}=96.8 \%\right)$, and in Europe it was $18.00 \%$ (95\% Cl: $8.58 \%-33.91 \%$; $\left.I^{2}=93.8 \%\right)$. Both of these were lower than the prevalence in Asia, which was 23.49\% (95\% Cl: $15.63 \%$ - 33.74\%; $\left.1^{2}=90.8 \%\right)$. The heterogeneity was high within studies from the same continent but not between groups (between continents; $p=0.7874)$.

Based on the profile of the studied individuals, our research revealed a predominance of women $(n=2802)$ compared to men $(n=2221)$, as shown in Table 1.

The average age of individuals with T2DM and individuals with MDD was approximately 59 years.
The time since diagnosis of T2DM and T2DM associated with MDD show a difference of 2.97 years between the first and second group. The analysis of glycosylated haemoglobin (HbA1c) showed differences between the same groups mentioned above. While the T2DM group had a mean of 7.72 , the group with MDD had an average of 8.01 in these test results.

Figure 3 summarizes the four case-control studies [48-51] according to their odds ratio (OR). In this analysis, we found a statistically significant association between the occurrence of MDD and T2DM (OR=2.06; 95\% Cl: 1.13 to 3.74; $p=0.0174$ ), and the heterogeneity between the studies was moderate $\left(I^{2}=66.4 \% ; \tau^{2}=0.2374 ; p=0.0304\right)$.

Table 1. Studies included in the meta-analysis.

\begin{tabular}{|c|c|c|c|c|c|c|}
\hline Autor & Country & Continent & $\begin{array}{l}\text { Patients } \\
\text { with MDD/ } \\
\text { Cases }\end{array}$ & $\begin{array}{c}\text { Prevalence (Cases) } \\
\%(95 \% \mathrm{Cl})\end{array}$ & $\begin{array}{l}\text { Men }(\mathrm{N}) \\
\text { T2DM or } \\
\text { MDD }\end{array}$ & $\begin{array}{l}\text { Women (N) } \\
\text { T2DM or } \\
\text { MDD }\end{array}$ \\
\hline Badawi, 2013 [39] & Canada & America & $139 / 1404$ & $9.90(8.39-11.58)$ & 657 & 747 \\
\hline Bai, 2008 [33] & China & Asia & $24 / 156$ & $15.38(10.11-22.02)$ & 80 & 76 \\
\hline Colunga-Rodriguez, 2008 [40] & Mexico & America & $30 / 450$ & $6.67(4.54-9.38)$ & 83 & 117 \\
\hline Dirmaier, 2010 [30] & Germany & Europe & $102 / 866$ & 11.78 (9.71 - 14.11) & 364 & 323 \\
\hline Fisher, 2010 [42] & USA & America & $71 / 463$ & $15.33(12.17-18.95)$ & 225 & 238 \\
\hline Fu-Espinosa, 2013 [43] & Mexico & America & $70 / 214$ & $32.71(26.47-39.44)$ & 70 & 144 \\
\hline Khamseh, 2011 [34] & Iran & Asia & $80 / 185$ & $43.24(35.99-50.71)$ & 89 & 96 \\
\hline Kogan, 2009 [44] & USA & America & $62 / 200$ & $31.00(24.67-37.91)$ & 60 & 140 \\
\hline Kokoszka, 2009 [31] & Poland & Europe & $34 / 101$ & $33.66(24.56-43.75)$ & 43 & 58 \\
\hline Madhu, 2013 [35] & India & Asia & $9 / 100$ & $9.00(4.20-16.40)$ & 34 & 66 \\
\hline Makine, 2009 [36] & Turkey & Asia & $36 / 151$ & $23.84(17.29-31.45)$ & 70 & 84 \\
\hline Merlino, 2010 [32] & Italy & Europe & $17 / 124$ & $13.71(8.19-21.04)$ & 64 & 60 \\
\hline Moreira, 2007 [45] & Brazil & America & $5 / 65$ & $7.69(2.54-17.05)$ & 12 & 53 \\
\hline Raval, 2010 [37] & India & Asia & $68 / 300$ & $22.67(18.05-27.83)$ & 147 & 153 \\
\hline Roca-Chiapas, 2013 [41] & Mexico & America & $36 / 65$ & $55.38(42.53-67.73)$ & 26 & 39 \\
\hline Skaff, 2009 [46] & USA & America & $84 / 452$ & $18.58(15.10-22.48)$ & 197 & 255 \\
\hline Wagner, 2010 [47] & USA & America & $63 / 153$ & $41.18(33.29-49.41)$ & 0 & 153 \\
\hline Yoshida, 2009 [38] & Japan & Asia & $36 / 105$ & $34.29(25.30-44.19)$ & - & - \\
\hline Total & & & $966 / 5554$ & $21.13(15.80-27.66)$ & 2221 & 2802 \\
\hline
\end{tabular}


Figure 3: Odds Ratios in case-control studies.

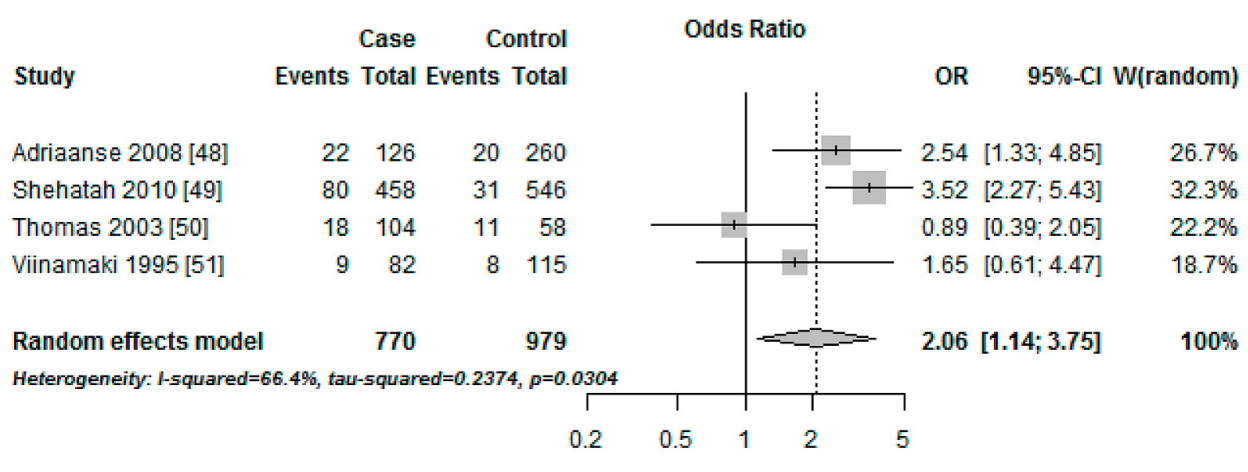

Figure 4: Meta-regression - Bubble plot by year of publication (a) time to diagnosis of T2DM (b), T2DM associated with MDD diagnostic time (c), average percentage of HbA1c (d); Q-Q Norm Plot by year of publication (e), time to diagnosis of T2DM (f), T2DM associated with MDD diagnostic time (g), average percentage of $\mathrm{HbA1c}(h)$.
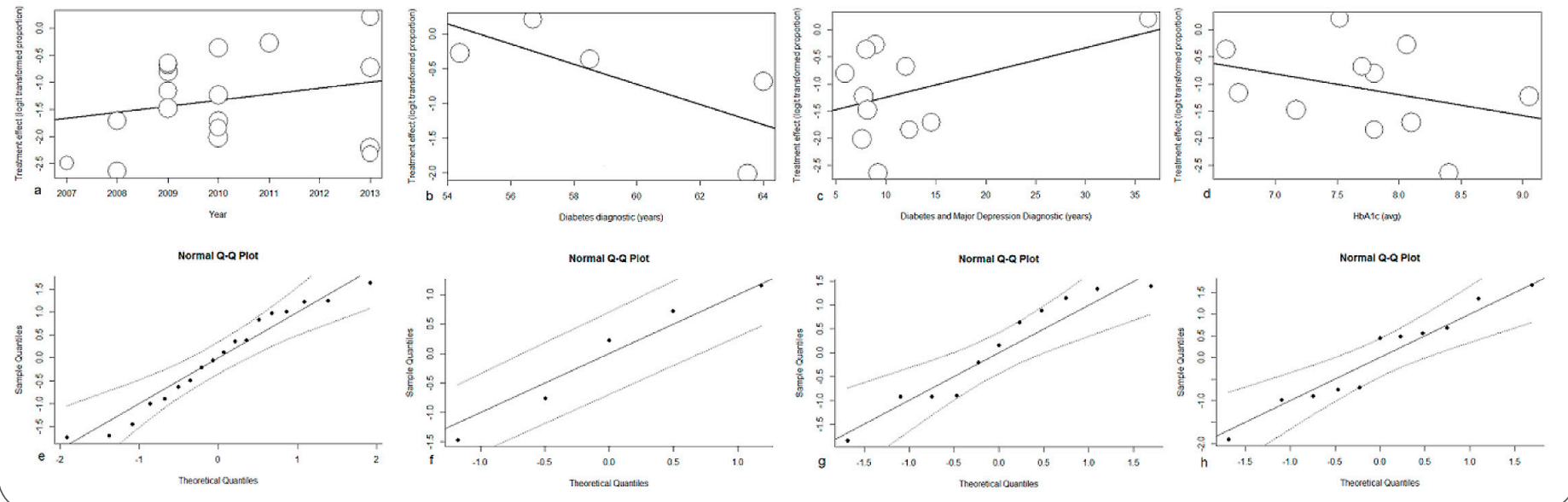

Figure 5: Funnel plot for the estimation of publication bias..

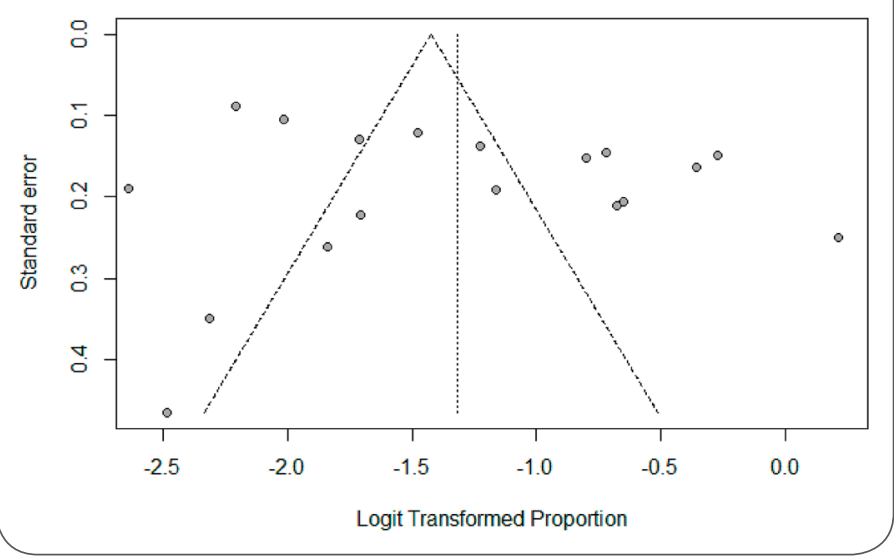

We explored the possible causes of heterogeneity in the 18 cross-sectional studies using metaregression analysis. We included clinical cofactors (age, duration of diabetes, duration of MDD and mean HbA1c) and publication year. Based on the meta-regression analysis, we found no evidence that these cofactors represented the cause of the heterogeneity (Figure 4).

The publication bias analysis of the 18 cross-sectional studies is shown in the presented funnel plot in Figure 5. In this graph, the logit of the prevalence of the analyzed studies is on the $x$ axis, and the standard error of each study is on the $y$ axis. The approximately symmetrical distribution of the points suggests an absence of publication bias that was confirmed by Egger's test ( $p=0.2345)$. 


\section{Discussion}

Psychiatric aspects related to DM have been studied and described for over 100 years [52] and can influence the disease course.

MDD results in several neurochemical and hormonal changes that have hyperglycemic effects and may cause disturbances in glucose metabolism. DM also has neurochemical effects on central nervous system neurotransmitters, such as serotonin, norepinephrine and dopamine, mimicking what happens in MDD and leading to decreased function of monoamines [53]. The combination of these biological changes in both conditions helps explain the frequency of depressive symptoms and MDD in people with DM.

The $21.13 \%(95 \% \mathrm{Cl}: 15.80 \%-27.66 \%)$ global average prevalence of MDD and T2DM revealed in our meta-analysis (prevalence ranged from 6.67\% (95\% Cl: $4.54 \%$ - 9.38\%) to $55.38 \%$ (95\% Cl: $42.53 \%$ - 67.73\%), showed high heterogeneity between the studies. To investigate the influence of study origin, a sensitivity analysis by continent was performed. This analysis showed that heterogeneity occurred within groups (between countries of the same continent) with Europe, 18.00\% (95\% Cl: 8.58\% -33.91\%; $\left.\left.\right|^{2}=93.8 \%\right)$; Asia, 23.49\% (95\% $\left.\mathrm{Cl}: 15.63 \%-33.74 \% ; \mathrm{I}^{2}=90.8 \%\right)$; and the Americas, $20.83 \%$ (95\% Cl: $13.12 \%-31.43 \%$; $\mathrm{I}^{2}=96.8 \%$ ), and did not occur between groups (between continents - $p=0.7874)$. Through our meta-regression analysis, we found no evidence that the cofactors considered represented the cause of the observed heterogeneity.

A recent study on depression in an elderly population in Mexico [54] showed that institutionalization and depression are closely associated. Another study [55] suggested that depression occurs more frequently in clinical populations; while depression is often found in $5 \%$ to $10 \%$ of those in outpatient care, these rates double in hospitalized individuals, ranging from $9 \%$ to $16 \%$.

Furthermore, T2DM, which is prevalent in $90 \%$ to $95 \%$ of people with diabetes and is also referred to as non-insulin diabetes, T2DM or adult onset diabetes [56], is not frequently diagnosed in the early stages of the disease. This is because hyperglycaemia develops gradually, and at early stages, it is often not severe enough for the patient to note any of the classic symptoms. However, this condition presents with an increased risk of developing macrovascular and microvascular complications [56, 57]. Therefore, we believed that the time from diagnosis may have had an influence on the differences found in our study, as the time from diagnosis of T2DM to the time of the survey ranged from less than six to over 30 years. In our meta-regression analysis, we observed this covariate to be significant $(p=0.0955)$ and can thus be associated with the presented heterogeneity $\left(r^{2}=49.53 \%\right)$.

At the same time, we observed in the studies that individuals with MDD associated with T2DM appear to have a longer disease duration.

We are also aware that the risk of developing T2DM increases with age, obesity and lack of physical activity [57]. Insulin secretion is deficient in these patients and insufficient to compensate for insulin resistance. While this can be improved by weight reduction and/or pharmacological treatment of hyperglycaemia, it is rarely restored to normal. The average age of the participants in the included studies indicated they were of an older population, which corroborates previous studies and reinforces the association of age-related complications of T2DM. Nevertheless, age is not the only determining factor related to depression [57]. DM is also associated with hypertension, and dyslipidemia. Furthermore, different prevalence rates in various racial and ethnic subgroups suggests there may be more of a genetic predisposition in T2DM than with the autoimmune form of diabetes (type 1). However, the genetics of T2DM is complex and not clearly defined $[56,57]$.

Since 2009, the level of glycosylated haemoglobin (HbA1c) has been included as an additional tool for the diagnosis of DM. HbA1c is an accurate measure of chronic glycemic levels and, among other advan- 
tages, is well accepted by patients because it does not require fasting or other prior preparation. It can also be used to guide treatment decisions [57].

The objective of treatment is glycemic control, which in turn, aims to prevent macrovascular and microvascular complications of long-term T2DM, preventing or minimizing most episodes of severe hypoglycaemia and enabling a good quality of life [58]. The American Diabetes Association (ADA), together with the American Association for the Study of Obesity (NAASO) and the American Society for Clinical Nutrition (ASN) suggested a decade ago that the initial therapy for the management of DM should be an intervention in lifestyle, including nutrition counselling with reduced saturated fat intake, increased intake of high-fibre foods, and an incentive to reduce body weight [59].

The changes in eating habits and adoption of interventions with multiple steps mentioned above, as well as regular insulin injections and daily glucose monitoring, can positively affect the health of the patient. However, individuals with DM should still consider that they will be living with a disease that has serious clinical complications for the rest of their lives. These considerations may influence the attitudes of individuals with DM. Moreover, according to Gross et al. [60], depressive symptoms can have a negative impact on important factors associated with self-care of patients with DM.

In terms of the methods used for the diagnosis of MDD, several validated scales were found in the studies included in our systematic review. These included the Beck Depression Inventory (BDI) first and second edition (BDI-II), the Center for Epidemiologic Studies Depression Scale (CES-D), the Geriatric Depression Scale (GDS) and its Thai version, the Taiwan Geriatric Depression Scale (TGDS), the Hamilton Depression Rating Scale (HDRS), the 10th edition of the International Classification of Diseases (ICD-10), the Patient Health Questionnaire - normal (PHQ-9) and short (PHQ-8) versions, the Structured Clinical Interview for DSM-IV (SCID), the Zung Depression
Scale (ZDS), and the Diagnostic Interview Schedule (DIS-IV) based on the DSM-IV.

These tools are useful for evaluating depression in research and in the clinic, showing similarities and differences between them. The semi-structured questionnaires that follow the diagnostic criteria of the DSM [4] are considered the gold standard for the diagnosis of MDD. For individuals with DM, there is concern that complaints related to fatigue, reduced libido, sleep disturbances, appetite and weight could be confused with the symptoms of MDD and result in higher scores in diagnostic evaluations. Of the available scales, only the BDI and the Depressive Cognition Scale (DCS) have been validated in clinical samples of individuals with DM [61, 62].

A recent study [63] comparing some of the abovementioned methods, proved possible differences in evaluation. However, the specificity and sensitivity of each test remained the same. In clarification of some of the differences between the scores, the author reported that the ZDS is a self-administered scale meant to be quickly applied and is generally used for monitoring and screening. Similarly, the CES-D scale [63], which has a different age cutoff point, was published in 1977 as a depression screening tool for the population in general and considers affective and somatic aspects of depression.

Another scale used widely since 1960 is the HDRS, which was developed to measure the severity of depression in hospitalized individuals and has undergone many changes over time. However, the HDRS evaluates primarily somatic symptoms and only a few cognitive or affective symptoms [63]. The difference in inclusion of somatic symptoms, emotional symptoms, or both in the depression assessment scales may have contributed to the difference in prevalence data from the studies included in our meta-analysis.

The BDI and the DCS are two scales that have been specifically validated in patients with DM. The BDI has a cutoff of 18 years of age for the general population and 16 years for individuals with diabe- 
tes. It is self-applied and considered quick and easy to use. However, completion requires cooperation and higher education. Our analysis indicated a difference in prevalence in the results of the original studies that may have been due to the different cutoff points [61].

The $\mathrm{BDI}$ is the most used self-rating scale and was created in 1961. It consists of 21 items on emotional, behavioural and somatic symptoms, with a specificity rate of $97 \%$ and a sensitivity of $99 \%$ for identifying patients with major depression [63]. In 1996, the second version of this instrument was validated, the BDI-II. The BDI-II has been compared to a more recent study and was still found to have test utility $[63,64]$.

The GDS is another scale for diagnosing depression. A study that reviewed publications using the GDS found that for older people without dementia, the test is accurate, easily administered and is the most recommended for cohort studies $[63,65]$. A systematic review of the PHQ-9 and the shortened version, PHQ-8, revealed that both are well-validated and brief measures for detecting and monitoring depression, anxiety and somatization [66]. The DIS-IV is the only fully structured questionnaire for use by non-clinical interviewers. It is fully structured in order to avoid deviations, and it allows for valid and reliable diagnoses of the major psychiatric disorders according to the DSM-IV [67].

The differences between the scales used in the included studies help clarify the heterogeneity revealed in our meta-analysis. Further emphasizing this issue, a meta-analysis [15] of 42 publications before 2000 revealed an association between Diabetes Melitus Type 1 and general depression and concluded that diabetes doubled the risk of depression. They also found that the scales used, in addition to sample characteristics, affected the reported prevalences [64].

We conclude that MDD was associated with individuals affected by T2DM in the included studies and that the prevalence was high, independent of geographic location. There was heterogeneity between the studies and therefore we recommend that the data presented here should be interpreted with caution. We emphasize the importance of standardization of MDD diagnosis methods to ensure the methodological quality of future studies.

\section{References}

1. Ashcroft FM, Rorsman P. Diabetes mellitus and the beta cell: the last ten years. Cell. 2012; 148(6): 1160-71.

2. Ali S, Stone MA, Peters JL, Davies MJ, Khunti K. The prevalence of co-morbid depression in adults with Type 2 diabetes: a systematic review and meta-analysis. Diabet Med. 2006; 23(11): 1165-73.

3. Barnard KD, Skinner TC, Peveler R. The prevalence of co-morbid depression in adults with Type 1 diabetes: systematic literature review. Diabet Med. 2006; 23(4): 445-8

4. American Psychiatry Association. Diagnostic and Statistical Manual of Mental disorders - DSM-5. 5th ed. Washington: American PsychiatricAssociation; 2013.

5. Mezuk B, Eaton WW, Albrecht S, Golden SH. Depression and type 2 diabetes over the lifespan: a meta-analysis. Diabetes Care. 2008; 31(12): 2383-90.

6. Nouwen A, Winkley K, Twisk J, Lloyd CE, Peyrot M, Ismail K, et al. Type 2 diabetes mellitus as a risk factor for the onset of depression: a systematic review and meta-analysis. Diabetologia. 2010; 53(12): 2480-6.

7. Nouwen A, Nefs G, Caramlau I, Connock M, Winkley K, Lloyd $C E$, et al. Prevalence of depression in individuals with impaired glucose metabolism or undiagnosed diabetes: a systematic review and meta-analysis of the European Depression in Diabetes (EDID) Research Consortium. Diabetes Care. 2011; 34(3): 752-62.

8. Black SA, Markides KS, Ray LA. Depression predicts increased incidence of adverse health outcomes in older Mexican Americans with type 2 diabetes. Diabetes Care. 2003; 26(10): 2822-8

9. Scherrer JF, Garfield LD, Chrusciel T, Hauptman PJ, Carney RM, Freedland $K E$, et al. Increased risk of myocardial infarction in depressed patients with type 2 diabetes. Diabetes Care. 2011; 34(8): 1729-34.

10. Zhang X, Norris SL, Gregg EW, Cheng YJ, Beckles G, Kahn HS. Depressive symptoms and mortality among persons with and without diabetes. Am J Epidemiol. 2005; 161(7): 652-60.

11. Justo LP, Calil HM. Depression - does it affect equally men and women? Arch clin psychiatry (São Paulo, Impr). 2006: 74-9.

12. Boing AF, Melo GR, Boing AC, Moretti-Pires RO, Peres KG, Peres MA. [Association between depression and chronic diseases: results from a population-based study]. Rev Saude Publica. 2012; 46(4): 617-23

13. Cooper JK, Harris Y, McGready J. Sadness predicts death in older people. J Aging Health. 2002; 14(4): 509-26. 
14. DiMatteo MR, Lepper HS, Croghan TW. Depression is a risk factor for noncompliance with medical treatment: meta-analysis of the effects of anxiety and depression on patient adherence. Arch Intern Med. 2000; 160(14): 2101-7.

15. Anderson RJ, Freedland KE, Clouse RE, Lustman PJ. The prevalence of comorbid depression in adults with diabetes: a meta-analysis. Diabetes Care. 2001; 24(6): 1069-78.

16. Gavard JA, Lustman PJ, Clouse RE. Prevalence of depression in adults with diabetes. An epidemiological evaluation. Diabetes Care. 1993; 16(8): 1167-78.

17. Hasan SS, Clavarino AM, Mamun AA, Doi SA, Kairuz T. Population impact of depression either as a risk factor or consequence of type 2 diabetes in adults: a meta-analysis of longitudinal studies. Asian J Psychiatr. 2013; 6(6): 460-72.

18. Roy T, Lloyd CE. Epidemiology of depression and diabetes: a systematic review. J Affect Disord. 2012; 142 Suppl: S8-21.

19. Deeks JJ BP, Gatsonis C. Cochrane Handbook for Systematic Reviews of Diagnostic Test Accuracy Version 1.0.0.: The Cochrane Collaboration; 2009.

20. Egger M, Smith GD, Altman D. Systematic reviews in health care: meta-analysis in context.: John Wiley\& Sons; 2008.

21. Higgins JP, Thompson SG, Deeks JJ, Altman DG. Measuring inconsistency in meta-analyses. Bmj. 2003; 327(7414): 557-60.

22. Huedo-Medina TB, Sanchez-Meca J, Marin-Martinez F, Botella J. Assessing heterogeneity in meta-analysis: Q statistic or 12 index? Psychol Methods. 2006; 11(2): 193-206.

23. DerSimonian R, Laird N. Meta-analysis in clinical trials. Control Clin Trials. 1986; 7(3): 177-88.

24. Deville WL, Buntinx F, Bouter LM, Montori VM, de Vet HC, van der Windt DA, et al. Conducting systematic reviews of diagnostic studies: didactic guidelines. BMC Med Res Methodol. 2002; 2: 9.

25. Egger M, Davey Smith G, Schneider M, Minder C. Bias in meta-analysis detected by a simple, graphical test. Bmj. 1997; 315(7109): 629-34

26. Sterne JA, Egger M. Funnel plots for detecting bias in metaanalysis: guidelines on choice of axis. J Clin Epidemiol. 2001; 54(10): 1046-55.

27. Langan D, Higgins JP, Gregory W, Sutton AJ. Graphical augmentations to the funnel plot assess the impact of additional evidence on a meta-analysis. J Clin Epidemiol. 2012; 65(5): 511 9.

28. Sterne JA, Sutton AJ, Ioannidis JP, Terrin N, Jones DR, Lau J, et al. Recommendations for examining and interpreting funnel plot asymmetry in meta-analyses of randomised controlled trials. Bmj. 2011; 343: d4002.

29. Whiting PF, Sterne JA, Westwood ME, Bachmann LM, Harbord $R$, Egger $M$, et al. Graphical presentation of diagnostic information. BMC Med Res Methodol. 2008; 8: 20.

30. Dirmaier J, Watzke B, Koch U, Schulz H, Lehnert H, Pieper L, et al. Diabetes in primary care: prospective associations between depression, nonadherence and glycemic control. Psychother Psychosom. 2010; 79(3): 172-8
31. Kokoszka A, Pouwer F, Jodko A, Radzio R, Mucko P, Bienkowska $J$, et al. Serious diabetes-specific emotional problems in patients with type 2 diabetes who have different levels of comorbid depression: a Polish study from the European Depression in Diabetes (EDID) Research Consortium. Eur Psychiatry. 2009; 24(7): 425-30.

32. Merlino G, Valente $M$, Serafini A, Fratticci L, Del Giudice A, Piani $A$, et al. Effects of restless legs syndrome on quality of life and psychological status in patients with type 2 diabetes. Diabetes Educ. 2010; 36(1): 79-87.

33. Bai YL, Chiou CP, Chang YY, Lam HC. Correlates of depression in type 2 diabetic elderly patients: a correlational study. Int J Nurs Stud. 2008; 45(4): 571-9.

34. Khamseh ME, Baradaran HR, Javanbakht A, Mirghorbani M, Yadollahi Z, Malek M. Comparison of the CES-D and PHQ-9 depression scales in people with type 2 diabetes in Tehran, Iran. BMC Psychiatry. 2011; 11: 61.

35. Madhu M, Abish A, Anu K, Jophin RI, Kiran AM, Vijayakumar K. Predictors of depression among patients with diabetes mellitus in Southern India. Asian J Psychiatr. 2013; 6(4): 313-7.

36. Makine C, Karsidag C, Kadioglu P, Ilkova H, Karsidag K, Skovlund $\mathrm{SE}$, et al. Symptoms of depression and diabetes-specific emotional distress are associated with a negative appraisal of insulin therapy in insulin-naive patients with Type 2 diabetes mellitus. A study from the European Depression in Diabetes [EDID] Research Consortium. Diabet Med. 2009; 26(1): 28-33.

37. Raval A, Dhanaraj E, Bhansali A, Grover S, Tiwari P. Prevalence \& determinants of depression in type 2 diabetes patients in a tertiary care centre. Indian J Med Res. 2010; 132: 195-200.

38. Yoshida S, Hirai M, Suzuki S, Awata S, Oka Y. Neuropathy is associated with depression independently of health-related quality of life in Japanese patients with diabetes. Psychiatry Clin Neurosci. 2009; 63(1): 65-72.

39. Badawi G, Page V, Smith KJ, Gariepy G, Malla A, Wang J, et al. Self-rated health: a predictor for the three year incidence of major depression in individuals with Type II diabetes. J Affect Disord. 2013; 145(1): 100-5.

40. Colunga-Rodriguez C, Alva JEG, Salazar-Estrada JG, ÁngelGonzález M. Diabetes Tipo 2 y Depresión em Guadalajara, México. RevSalud Publica. 2008: 137-49.

41. De la Roca-Chiapas JM, Hernandez-Gonzalez M, Candelario M, Villafana Mde L, Hernandez E, Solorio S, et al. Association between depression and higher glucose levels in middle-aged Mexican patients with diabetes. Rev Invest Clin. 2013; 65(3): 209-13.

42. Fisher L, Glasgow RE, Strycker LA. The relationship between diabetes distress and clinical depression with glycemic control among patients with type 2 diabetes. Diabetes Care. 2010; 33(5): 1034-6.

43. Fu-Espinosa M, Trujillo-Olivera LE. Depressive disorder and issues related to DiabetIMSS beneficiaries. Rev Med Inst Mex Seguro Soc. 2013; 51(1): 80-5.

44. Kogan SM, Brody GH, Chen YF. Depressive symptomatology mediates the effect of socioeconomic disadvantage on $\mathrm{HbA}(1 \mathrm{c})$ among rural African Americans with type 2 diabetes. J Psychosom Res. 2009; 67(4): 289-96. 
45. Moreira RO, Papelbaum M, Fontenelle LF, Appolinario JC, Ellinger VC, Coutinho WF, et al. Comorbidity of psychiatric disorders and symmetric distal polyneuropathy among type II diabetic outpatients. Braz J Med Biol Res. 2007; 40(2): 269-75.

46. Skaff MM, Mullan JT, Almeida DM, Hoffman L, Masharani U, Mohr $D$, et al. Daily negative mood affects fasting glucose in type 2 diabetes. Health Psychol. 2009; 28(3): 265-72.

47. Wagner JA, Tennen $H$, Osborn CY. Lifetime depression and diabetes self-management in women with Type 2 diabetes: a case-control study. Diabet Med. 2010; 27(6): 713-7.

48. Adriaanse MC, Dekker JM, Heine RJ, Snoek FJ, Beekman AJ, Stehouwer CD, et al. Symptoms of depression in people with impaired glucose metabolism or Type 2 diabetes mellitus: The Hoorn Study. Diabet Med. 2008; 25(7): 843-9.

49. Shehatah A, Rabie MA, Al-Shahry A. Prevalence and correlates of depressive disorders in elderly with type 2 diabetes in primary health care settings. J Affect Disord. 2010; 123(1-3): 197-201.

50. Thomas J, Jones G, Scarinci I, Brantley P. A descriptive and comparative study of the prevalence of depressive and anxiety disorders in low-income adults with type 2 diabetes and other chronic illnesses. Diabetes Care. 2003; 26(8): 2311-7.

51. Viinamaki H, Niskanen L, Uusitupa M. Mental well-being in people with non-insulin-dependent diabetes. Acta Psychiatr Scand. 1995; 92(5): 392-7.

52. Maudsley H. The patology of mind. 3 ed. New York: Appleton; 1979.

53. Leedom L, Meehan WP, Procci W, Zeidler A. Symptoms of depression in patients with type II diabetes mellitus. Psychosomatics. 1991; 32(3): 280-6.

54. Tavano-Colaizzi L, Arroyo P, Loria A, Perez-Lizaur AB, PerezZepeda MU. Clinimetric testing in mexican elders: associations with age, gender, and place of residence. Front Med (Lausanne). 2014; 1: 36.

55. Katon WJ. Clinical and health services relationships between major depression, depressive symptoms, and general medical illness. Biol Psychiatry. 2003; 54(3): 216-26.

56. American Diabetes Association. Diagnosis and Classification of Diabetes Mellitus: Diabetes Care; 2010.

57. The International Expert Committee. International Expert Committee Report on the Role of the A1C Assay in the Diagnosis of Diabetes: Diabetes Care; 2009.

58. Ismail-Beigi F. Pathogenesis and glycemic management of type 2 diabetes mellitus: a physiological approach. Arch Iran Med. 2012; 15(4): 239-46.

59. Klein S, Sheard NF, Pi-Sunyer X, Daly A, Wylie-Rosett J, Kulkarni $K$, et al. Weight management through lifestyle modification for the prevention and management of type 2 diabetes: rationale and strategies: a statement of the American Diabetes Association, the North American Association for the Study of Obesity, and the American Society for Clinical Nutrition. Diabetes Care. 2004; 27(8): 2067-73.

60. Gross R, Olfson M, Gameroff MJ, Carasquillo O, Shea S, Feder A, et al. Depression and glycemic control in Hispanic primary care patients with diabetes. J Gen Intern Med. 2005; 20(5): 460-6.
61. Lustman PJ, Clouse RE, Griffith LS, Carney RM, Freedland KE. Screening for depression in diabetes using the Beck Depression Inventory. Psychosom Med. 1997; 59(1): 24-31.

62. Zauszniewski JA, Chung C, Krafcik K, Sousa VD. Psychometric testing of the depressive cognition scale in women with type 2 diabetes. J Nurs Meas. 2001; 9(1): 61-72.

63. Williams JW, Jr., Pignone M, Ramirez G, Perez Stellato C. Identifying depression in primary care: a literature synthesis of case-finding instruments. Gen Hosp Psychiatry. 2002; 24(4): 225-37.

64. Arnarson TO, Olason DT, Smari J, Sigurethsson JF. The Beck Depression Inventory Second Edition (BDI-II): psychometric properties in Icelandic student and patient populations. Nord J Psychiatry. 2008; 62(5): 360-5.

65. Allen J, Annells M. A literature review of the application of the Geriatric Depression Scale, Depression Anxiety Stress Scales and Post-traumatic Stress Disorder Checklist to community nursing cohorts. J Clin Nurs. 2009; 18(7): 949-59.

66. Kroenke K, Spitzer RL, Williams JB, Lowe B. The Patient Health Questionnaire Somatic, Anxiety, and Depressive Symptom Scales: a systematic review. Gen Hosp Psychiatry. 2010; 32(4): 345-59.

67. Segal DL. Diagnostic Interview Schedule for DSM-IV (ADIS-IV); 2010.

\section{Publish in International Archives of Medicine}

International Archives of Medicine is an open access journal publishing articles encompassing all aspects of medical science and clinical practice. IAM is considered a megajournal with independent sections on all areas of medicine. IAM is a really international journal with authors and board members from all around the world. The journal is widely indexed and classified Q1 in category Medicine. 